\title{
Artikel
}

\section{Overzicht toekomstige wijzigingen in de Mededingingswet}

\author{
Stephanie The en Vivian van Weperen*
}

\section{Introductie}

Op 17 maart 2021 heeft toenmalig staatssecretaris Keijzer van Economische Zaken en Klimaat (EZK) een wetsvoorstel ingediend strekkende tot een aantal wijzingen in de Mededingingswet. ${ }^{1}$

De voorgestelde wijzigingen zien met name op drie onderdelen van de Mededingingswet. In de eerste plaats wordt voorgesteld dat de Mededingingswet expliciet de voorwaardelijke toepasselijkheid van het kartelverbod op gedragingen in het kader van het gemeenschappelijk landbouwbeleid en het gemeenschappelijk visserijbeleid zal gaan benoemen. Artikel 42 Verdrag betreffende de werking van de Europese Unie (VWEU) bepaalt namelijk dat de mededingingsregels slechts in zoverre van toepassing zijn op deze sector als nader bepaald in het voornoemd beleid. Hoewel deze systematiek nu al doorwerkt in de Nederlandse Mededingingswet, wordt met de voorgestelde explicitering beoogd - in combinatie met toekomstige handreikingen en een breder pakket aan maatregelen - een positieve bijdrage te leveren aan de positie van de boer in de agrarische keten. In de tweede plaats bevat het wetsvoorstel een aantal wijzigingen in het kader van het concentratietoezicht, die vooral gericht zijn op nadere aansluiting bij regels die reeds gelden op Europese niveau. Ten slotte is beoogd om bestaande wetgeving in het kader van privaatrechtelijke handhaving van het mededingingsrecht ook van toepas-

Mr. S. The is partner en advocaat bij De Brauw Blackstone Westbroek. Mr. V.Y.H. van Weperen is senior associate en advocaat bij De Brauw Blackstone Westbroek.

1 Kamerstukken II 2020/21, 35770, nr. 2.

sing te verklaren op zuiver nationale overtredingen van het mededingingsrecht.

De voorgestelde wijzigingen zijn met name technisch van aard. Het wetsvoorstel geeft desalniettemin een inkijk in hoe de regering de rol van de Mededingingswet ziet in de maatschappij - met name in het kader van de landbouwsector. Hierna zullen de bovengenoemde voorgestelde wijzingen achtereenvolgens worden besproken. Hierbij wordt steeds ingegaan op de juridische en maatschappelijke context waarin de voorgestelde wijzingen moeten worden bezien. Waar relevant wordt ook aandacht besteed aan reacties uit de openbare consultaties.

\section{Voorgestelde wijzingen ten aanzien van samenwerkingen in de landbouwsector en de visserij}

\section{Het EU-rechtelijk kader}

Het ontstaan van het Europees landbouwbeleid gaat terug tot de jaren zestig van de vorige eeuw. Zowel tijdens als na de Tweede Wereldoorlog was sprake van voedseltekorten en het Gemeenschappelijk Landbouwbeleid moest er onder meer voor zorgen dat de Europese Gemeenschap zelfvoorzienend zou zijn. Door het beleid werden interne handelsbarrières opgeheven en er kwam onder meer een systeem dat agrariërs een minimumprijs en afzet van producten garandeerde.

Sinds 1962 geniet de landbouwsector een speciale status binnen het Europees mededingingsrecht. Hoofdstuk 2 titel 3 van het VWEU voorziet in de bepaling van een gemeenschappelijk landbouwbeleid (GLB) en gemeenschappelijk visserijbeleid (GVB) als onderdeel van 
de Europese interne markt. Het GLB en het GVB moeten enerzijds voorzien in het ondersteunen van de landbouwers en het garanderen van een redelijk inkomen en anderzijds zorgen voor betaalbare levensmiddelen (art. 39 VWEU). Om dit mogelijk te maken wordt een gemeenschappelijke ordening (GMO) van landbouwmarkten tot stand gebracht, die onder andere bestaat uit gemeenschappelijke regels inzake mededinging (art. 40 lid 1 onder a VWEU). Artikel 42 VWEU speelt hierin een centrale rol. Deze bepaling verleent namelijk een zekere vorm van voorrang aan het landbouwrecht: het is op grond van dit artikel de Europese wetgever die bepaalt wanneer de mededingingsregels van toepassing zijn op de voortbrenging van en de handel in landbouwproducten. Een belangrijke rol is daarnaast ook weggelegd voor de zogenoemde producentenorganisaties (PO's): verenigingen van primaire producenten in de landbouwsector die doelstellingen uit het Europese landbouwbeleid nastreven en onder meer door het plannen van de productie en het bundelen van het aanbod tegenwicht kunnen bieden aan de macht van de vraagzijde in de markt.

Hoewel de ogenschijnlijk eenvoudige hoofdregel uit artikel 42 VWEU op zichzelf niet meteen vragen oproept, is het tegendeel waar. Het snijvlak tussen het landbouwrecht en de mededingingsregels wordt namelijk gekenmerkt door een grote mate van rechtsonzekerheid en onduidelijkheid, waarbij in eerdere edities van dit tijdschrift ook is stilgestaan. ${ }^{2}$ Een deel van de rechtsonzekerheid vloeit allereest voort uit de systematiek van de bestaande regelgeving. Er zijn meerdere GMO-verordeningen geïmplementeerd op basis van artikel $42 \mathrm{VWEU}$, waarvan de belangrijkste Verordening (EU) nr. 1308/2013 is. ${ }^{3}$ Deze regelt namelijk de toepassing van de mededingingsregels op de voortbrenging van en de handel in landbouwproducten. In deze verordeningen is bepaald dat de mededingingsregels in beginsel wél van toepassing zijn op de landbouw- en visserijsector, behalve in bepaalde in de verordening toegelichte gevallen. In de loop der jaren is dit uitgegroeid tot een ingewikkeld web van allerlei algemene en specifieke(re) uitzonderingen op het kartelverbod.

Daarnaast heerste er tot een aantal jaar geleden onduidelijkheid over de juridische status van bepalingen in de GMO-verordening. Deze vraag werd door het Hof van Justitie beantwoord in het in dit tijdschrift al eerder besproken Witlof-arrest. ${ }^{4}$ Kort gezegd oordeelde het Hof van Justitie dat voor wat betreft de landbouwsector geen sprake is van een vrijstelling van het kartelverbod, maar een uitsluiting. In de eerste plaats lijkt dit juridisch-tech-

2 M. Litjens \& T. van Rhijn, 'Samenwerking in de landbouw en mededingingsregels', M\&M 2019, afl. 1; G. van Heezik, 'Witlofkartelzaak: mededingingsregels niet van toepassing op inherente beperkingen van de taakuitoefening door erkende (unies van) producentenorganisaties', M\&M 2018, afl. 2.

3 Verordening (EU) nr. 1308/2013 van het Europees Parlement en de Raad 17 december 2013 tot vaststelling van een gemeenschappelijke ordening van de markten voor landbouwproducten en tot intrekking van de Verordeningen (EEG) nr. 922/72, (EEG) nr. 234/79, (EG) nr. 1037/2001 en (EG) nr. 1234/2007 van de Raad (PbEU 2013, L 347/671).

4 HvJ EU 14 november 2017, zaak C-671/15, ECLI:EU:C:2017:860 (Président de l'Autorité de la Concurrence/APVE e.a.). nisch relevant. De status van 'uitsluiting' betekent dat de gedragingen die zijn beschreven in de GMO-verordeningen geheel zijn uitgesloten van de werking van de mededingingsregels (en dus hoeft er ook niet getoetst te worden aan artikel 101 lid 3 VWEU). Waren de gedragingen, daarentegen, als vrijgesteld gezien, dan waren de bepalingen in de GMO-verordening rechtvaardigingen zoals bedoeld in artikel 101 lid 3 VWEU geweest, waar het voornaamste doel de consumentenwelvaart is. Dit verschil heeft een praktische uitwerking - met name op EU-niveau - aangezien dit betekent dat nieuwe regelgeving voor de landbouwsector niet onderhevig is aan de toets uit artikel 101 lid 3 VWEU, maar 'slechts' dient bij te dragen aan één van de in artikel 39 VWEU opgenomen doelen van het GLB en GVB. Het primaat van de doelen van het GLB en GVB is dus in het Witlof-arrest nogmaals door het Hof van Justitie bevestigd.

\section{Het wetsvoorstel in context: de positie van de boer in de agrarische keten}

Hoewel de voorwaardelijke toepasselijkheid van het kartelverbod op gedragingen in het kader van het GLB en GVB al sinds 1962 in het EU-recht bestaat, is deze niet eerder expliciet opgenomen in de Mededingingswet (Mw). Na doorvoering van de wetswijziging komt hier verandering in, door de toevoeging van een nieuw artikel 11a:

'1. Voor overeenkomsten, besluiten en gedragingen als bedoeld in artikel 6, eerste lid, die betrekking hebben op de voortbrenging van en de handel in landbouwproducten, bedoeld in artikel 42 van het Verdrag, geldt artikel 6, eerste lid, uitsluitend in de gevallen ten aanzien waarvan bij of krachtens een verordening van het Europees Parlement en de Raad van de Europese Unie is bepaald dat artikel 101 van het Verdrag van toepassing is op die overeenkomsten, besluiten en gedragingen.

2. Onze Minister van Landbouw, Natuur en Voedselkwaliteit doet mededeling in de Staatscourant van de gevallen, bedoeld in het eerste lid.'

Hoewel deze bepaling haar oorsprong heeft in het EUrecht, wordt met de beoogde wetswijziging uitvoering gegeven aan een al langer bestaand voornemen om de positie van de boer te versterken. De afgelopen jaren is het landschap waarin de Nederlandse boeren en tuinders zich begeven immers letterlijk en figuurlijk steeds ingewikkelder geworden. Dit komt deels door eigenschappen die inherent zijn aan de landbouwsector: de productie is sterk onderhevig aan de (steeds extremere) weersomstandigheden en het is voor boeren over het algemeen lastig om de productie in korte tijd aan de vraag aan te passen. Bovendien zijn agrarische ondernemingen doorgaans relatief klein, terwijl in de schakels verderop in de keten - bijvoorbeeld vanwege inkooporganisaties - vaak een kleiner aantal spelers actief is. Zo constateerde het Planbureau voor de Leefomgeving in 2012 dat de onderhandelingsmacht tussen verschillende partijen in de agrarische ketens onevenwichtig verdeeld kan zijn, met als gevolg dat de positie van boeren en 
tuinders onder (prijs)druk staan. Boeren en tuinders moeten daarnaast voldoen aan steeds hogere kwaliteitsen duurzaamheidseisen die zowel door de overheid als door de markt (de consumenten) worden gesteld, wat het voor kleinschalige agrarische bedrijven niet eenvoudiger maakt zich staande te houden.

Het verbeteren van de positie van de boer werd ook in 2017 op de agenda gezet, toen de toenmalige regering in het regeerakkoord 'Vertrouwen in de toekomst' ${ }^{5}$ aankondigde samenwerking in de land- en tuinbouw expliciet toe te willen staan om zo 'de ongelijke machtsverhouding in de keten te compenseren'. Hoewel het mededingingsrecht - en in het bijzonder het kartelverbod inderdaad vaak door boeren als belemmerend wordt ervaren, moet het voorgestelde artikel 11a Mw niet als een opzichzelfstaand voornemen of middel worden gezien. Het wetsvoorstel is namelijk onderdeel van een breder pakket aan maatregelen. Dit wordt door de minister van Landbouw, Natuur en Voedselkwaliteit (LNV) ook toegelicht in haar Kamerbrief hierover. ${ }^{6}$

Het pakket bestaat onder meer uit (1) een handreiking over samenwerkingsmogelijkheden, (2) twee andere wetsvoorstellen - namelijk het wetsvoorstel Ruimte voor duurzaamheidsinitiatieven en de Wet oneerlijke handelspraktijken landbouw- en voedselvoorzieningsketen, ${ }^{7}$ (3) de agro-nutrimonitor van de Autoriteit Consument en Markt (ACM) en (4) de implementatie van de Europese Uitvoeringsverordening (EU) 2017/1185. Het is uiteindelijk dit pakket - dat enerzijds is gericht op het 'bundelen' van de krachten van de boeren en anderzijds op toezicht en openheid - dat er uiteindelijk voor moet zorgen dat boeren en tuinders minder druk ervaren.

\section{Beoordeling}

Hoewel het wetsvoorstel ten aanzien van de landbouwsector slechts de toevoeging van een enkele bepaling omvat, kan hier wel degelijk het een en ander over gezegd worden, zo blijkt ook uit de consultatiereacties. Hieronder wordt ten aanzien van het nieuwe artikel 11a Mw achtereenvolgens besproken: (1) de opbouw en volledigheid van de bepaling en (2) de toegevoegde waarde voor de primaire producenten in de agrarische sector (de boeren en tuinders).

\section{- $\quad$ Opbouw en volledigheid van de bepaling}

De opbouw van het voorgestelde artikel 11a Mw is betrekkelijk eenvoudig: lid 1 verwijst naar de voorrangsregel voor de landbouwsector uit artikel 42 VWEU en lid 2 beschrijft dat de minister van LNV dit nader zal toelichten in de Staatscourant.

De formulering van lid 2 sluit echter niet aan bij de systematiek van artikel 42 VWEU en de GMO-verordeningen (wat blijkens de memorie van toelichting wel de bedoeling leek te zijn). Volgens de memorie van toelich-

Regeerakkoord 'Vertrouwen in de Toekomst', p. 34, 39, 44.

Kamerstukken I/ 2017/18, 28625 nr. 257.

De Wet oneerlijke handelspraktijken landbouw- en voedselvoorzieningsketen (Stb. 2021, 178) is in werking getreden met ingang van 1 november 2021. Met deze wet is Richtlijn (EU) 2019/633 geïmplementeerd. ting zal de minister van LNV in de Staatscourant immers mededelen 'welke gevallen zijn uitgesloten van het kartelverbod'. Lid 2 lijkt echter te suggereren dat de minister de gevallen zal mededelen die wél onder het kartelverbod vallen. Een terechte vraag die in meerdere consultatiereacties terugkomt, is of dit dan zou betekenen dat de niet-benoemde gevallen automatisch zijn toegestaan (omdat deze dan níet onder het kartelverbod zouden vallen). De benadering uit de memorie van toelichting lijkt daarom logischer dan een strikte lezing van artikel 11a lid $2 \mathrm{Mw}$.

Ervan uitgaande dat de minister van LNV de uitzonderingen zal meedelen, blijft echter onduidelijk welke uitzonderingen hierin zullen worden meegenomen. De GMO-verordening alleen beslaat al honderden pagina's en bevat naast enkele hoofdregels ook productspecifieke uitzonderingen (bijvoorbeeld ten aanzien van zuivelproducten), dus het zal een uitdaging worden om dit op een overzichtelijke manier vorm te geven.

Ten slotte valt op dat artikel 11a lid $1 \mathrm{Mw}$ slechts verwijst naar uitzonderingen op het kartelverbod, terwijl artikel 42 VWEU verwijst naar 'het hoofdstuk over regels betreffende de mededinging'. Het kabinet vond het echter niet nodig om een verwijzing naar artikel $24 \mathrm{Mw}$ op te nemen in het wetsvoorstel, aangezien er geen gedragingen in de landbouw- en visserijsector zouden zijn uitgesloten van het verbod op misbruik van een machtspositie. ${ }^{8}$ Helemaal waterdicht lijkt die redenering echter niet. Zo bevat de GMO-verordening voor de visserijsector $^{9}$ in artikel 40 en 41 bepalingen die het toepassingsbereik van het verbod van economische machtspositie beogen te reguleren. De ACM merkt in dat verband op dat het wenselijk zou zijn als het kabinet opheldering geeft over de vraag of met het wetsvoorstel ook de regulering van de doorwerking van artikel 102 en 106 VWEU in het Nederlandse mededingingsrecht is beoogd. Dit lijkt het geval te zijn, aangezien de memorie van toelichting verduidelijkt dat indien in de toekomst sprake is van uitsluiting van gedragingen in de landbouw- en visserijsector van het verbod op misbruik van een machtspositie op EU-niveau, de Mededingingswet hierop zal worden aangepast. ${ }^{10}$

- Toegevoegde waarde voor de primaire producenten in de agrarische sector

Op dit moment werken de uitsluitingen van het kartelverbod die op grond van artikel 42 VWEU gelden al door in de Mededingingswet. Artikel $12 \mathrm{Mw}$ bepaalt namelijk dat het kartelverbod niet geldt voor gedragingen waarvoor krachtens een verordening van de Raad of van de Europese Commissie artikel 101 lid 1 VWEU buiten toepassing is verklaard. De toevoeging van het nieuwe arti-

Verordening (EU) nr. 1379/2013 van het Europees Parlement en de Raad van 11 december 2013 houdende een gemeenschappelijke marktordening voor visserijproducten en aquacultuurproducten, tot wijziging van Verordeningen (EG) nr. 1184/2006 en (EG) nr. 1224/2009 van de Raad en tot intrekking van Verordening (EG) nr. 104/2000 van de Raad (PbEU 2013, L 354/1).

10 MvT, p. 6 
kel 11a Mw is dan ook vooral technisch van aard: voor wat betreft de reikwijdte van artikel 42 VWEU en de doorwerking hiervan verandert er niets. Vanuit het oogpunt van rechtszekerheid en praktisch nut is dit jammer, aangezien de onduidelijkheid van de huidige regelgeving een van de factoren is die op dit moment door de agrarische sector als belemmerend wordt ervaren. ${ }^{11}$ Het voornaamste kritiekpunt dat doorklinkt in de consultatiereacties is dan ook dat het wetsvoorstel niet zal leiden tot (meer) zekerheid voor primaire producenten. Hoewel de respondenten van de internetconsultatie zich over het algemeen positief uitlaten over de invoering van artikel $11 \mathrm{a}$, wordt in het merendeel van de reacties terecht opgemerkt dat artikel 11a Mw op zichzelf niet de duidelijkheid zal verschaffen waaraan de landbouwsector nu juist zo'n behoefte heeft, dan wel zal leiden tot een versterking van de positie van primaire producenten in de keten. Deze kritische noten dienen op twee punten wel te worden genuanceerd. In de eerste plaats blijkt uit onderzoek ${ }^{12}$ dat veel ondernemers in de agrarische sector wel degelijk onbekend zijn met de mogelijkheden voor onderlinge samenwerking. Toevoeging van artikel 11a Mw is dan in ieder geval een eerste stap in het creëren van meer bewustwording, al is het twijfelachtig of een wetswijziging het meest effectieve middel hiervoor is. In de tweede plaats is de onduidelijke formulering van de geldende uitzonderingen en de daaruit voortvloeiende onzekerheid over de toepassing ervan, een vraagstuk dat primair op EU-niveau zal moeten worden opgelost. Het is in dit kader niet aan de nationale wetgever om zelfstandig uitleg te geven over punten waarop het EU-recht onduidelijkheden geeft. De lat moet in een dergelijke situatie dan ook niet te hoog worden gelegd, aangezien de rol van de wetgever beperkt is. Bovendien kondigt de memorie van toelichting aan dat de minister van LNV, de staatssecretaris van EZK en de ACM praktische invulling zullen geven aan het wetsvoorstel in de vorm van een nog te publiceren handreiking. Publicatie van deze handreiking wordt begin 2022 verwacht. ${ }^{13}$ Het zal dan ook vooral deze handreiking zijn die de primaire producenten de benodigde handvatten moet geven om in concrete gevallen te bepalen wat de mogelijkheden zijn voor onderlinge samenwerking.

\section{Wijzigingen ten aanzien van de concentratiecontrole}

Het wetsvoorstel bevat ook een vijftal wijzingen ten aanzien van de concentratiecontrole. De belangrijkste voorstellen betreffen: (1) de omzetberekening van afhankelijke economische transacties (art. 30 lid $2 \mathrm{Mw}$ ), (2) de systematiek bij vergunningverlening (art. $37 \mathrm{Mw}$ )

11 Zie ook Wageningen Economic Research, Positie primaire producent in de keten, juni 2018. Zie: f4257cbd-4667-4fae-ae43-c65ea0599a9a_ 2018-027_Baltussen_def.pdf (wur.nl).

12 Zie Positie primaire producent in de keten.

13 MvT, p.7. en (3) de uitzondering op de standstill-verplichting bij een openbaar bod.

De voorgestelde wijzingen beogen de Mededingingswet beter aan te laten sluiten bij de EG-concentratieverordening. ${ }^{14}$ Bij de inrichting van het Nederlandse concentratietoezicht is aansluiting gezocht bij het Europese concentratietoezicht. ${ }^{15}$ Op bepaalde onderdelen komen de bepalingen over het concentratietoezicht in de Mededingingswet zowel tekstueel als inhoudelijk niet geheel overeen met het Europeesrechtelijk kader; met het wetsvoorstel wordt beoogd dit te herstellen.

Omzetberekening van afhankelijke economische transacties (art. 30 lid $2 \mathrm{Mw}$ )

Zoals bekend verzet artikel 30 lid 2 Mw zich tegen de zogenoemde 'salamitactiek', waarbij één concentratie in verschillende transacties wordt opgeknipt met als doel om onder de omzetdrempels van het concentratietoezicht te blijven en zodoende het concentratietoezicht te omzeilen.

Het wetsvoorstel bevat de volgende beoogde wijziging van artikel 30 lid $2 \mathrm{Mw}$ :

\begin{tabular}{|c|c|}
\hline Huidig & Voorgestelde wijziging \\
\hline $\begin{array}{l}\text { Twee of meer verwervingen als } \\
\text { bedoeld in de eerste volzin die } \\
\text { plaatsvinden binnen een door de } \\
\text { Autoriteit Consument en Markt in } \\
\text { aanmerking te nemen periode en } \\
\text { die afhankelijk van elkaar zijn of } \\
\text { op een economische wijze zodanig } \\
\text { met elkaar zijn verbonden dat } \\
\text { deze verwervingen als één } \\
\text { verwerving zouden moeten } \\
\text { worden beoordeeld, worden } \\
\text { beschouwd als één concentratie } \\
\text { die tot stand gebracht wordt op de } \\
\text { dag van de laatste transactie. }\end{array}$ & $\begin{array}{l}\text { Gecursiveerde tekst wordt } \\
\text { vervangen door: } \\
\text { die binnen een periode van } \\
\text { twee jaar plaatsvinden tussen } \\
\text { dezelfde personen of onderne- } \\
\text { mingen. }\end{array}$ \\
\hline
\end{tabular}

Het wetsvoorstel bevat twee wijzigingen van artikel 30 lid $2 \mathrm{Mw}$. De eerste wijziging ziet op de periode waarbinnen meerdere verwervingen van delen van een onderneming plaatsvinden, en die daarom - voor de omzetberekening - als één transactie moeten worden beschouwd. In de eerste instantie had de wetgever ervoor gekozen om, in afwijking van artikel 5 lid 2 EG-concentratieverordening, niet uit te gaan van een periode van twee jaar. In plaats hiervan werd de keuze hiervoor aan de ACM gelaten. De belangrijkste reden hiervoor was te voorkomen dat marktpartijen hun transacties zo zouden vormgeven dat deze buiten de termijn van twee jaar zouden vallen en daarom niet zouden kunnen worden beschouwd als één transactie. ${ }^{16}$ Om meer duidelijkheid te geven aan marktpartijen wordt nu voorgesteld om aan

14 Verordening (EG) nr. 139/2004 van de Raad van 20 januari 2004 betreffende de controle op concentraties van ondernemingen (PbEU 2004, L 24/1).

15 Kamerstukken II 1995/96, 24707, nr. 3, p. 32.

16 Kamerstukken II 2004/05, 30071, nr. 3, p. 19 (MvT). 
te sluiten bij de EG-concentratieverordening. In de praktijk ging de ACM overigens al uit van een periode van twee jaar, dus in de praktijk zal deze wijziging geen verandering teweegbrengen.

De tweede wijziging in artikel 30 lid $2 \mathrm{Mw}$ ziet op de aard van de verwervingen die door de ACM eventueel moeten worden beschouwd als één concentratie. In de huidige bepaling wordt uitgegaan van de theorie van de economische verbondenheid en niet, zoals in artikel 5 lid 2 EG-concentratieverordening, van verwervingen die binnen een periode van twee jaar plaatsvinden tussen dezelfde personen of ondernemingen. Met de voorgestelde wijziging wordt lid 2 wat betreft de systematiek meer in lijn gebracht met de EG-concentratieverordening. De leer van 'afhankelijke transacties' speelt immers, zo blijkt ook uit de Consolidated Notice, ${ }^{17}$ juist een rol bij de afbakening van het begrip 'concentratie'. Zoals ook al terecht opgemerkt in onder meer Tekst en Commentaar ${ }^{18}$ zijn de voorwaarden van het huidige artikel 30 lid $2 \mathrm{Mw}$ op dit moment gelijkluidend aan de algemene voorwaarden voor het concentratiebegrip in artikel $27 \mathrm{Mw}$ (en daarmee art. 1 lid 3 EG-concentratieverordening), waardoor de toevoeging van de leer van de afhankelijke transacties in artikel 30 lid $2 \mathrm{Mw}$ niet duidelijk is. Met de voorgestelde wijziging wordt artikel 30 lid $2 \mathrm{Mw}$ tekstueel en inhoudelijk weer in lijn gebracht met artikel 5 lid 2 EG-concentratieverordening.

\section{Systematiek bij vergunningverlening (art. 37 Mw)}

Artikel $37 \mathrm{Mw}$ bepaalt de drie mogelijke 'uitkomsten' van een concentratiemelding: (1) de ACM keurt een voorgestelde concentratie onvoorwaardelijk goed en de concentratie mag direct worden voltrokken, (2) de ACM oordeelt dat een vergunning is vereist en (3) de ACM keurt de concentratie onder voorwaarden goed. Uit het huidige lid 6 volgt dat ingeval de ACM een concentratie in de meldingsfase onder voorwaarden goedkeurt, aan de gestelde voorwaarden moet zijn voldaan voordat de concentratie mag worden voltrokken. Wanneer structurele remedies worden opgelegd in de meldingsfase, geldt onder het huidige regime dat bijvoorbeeld een af te stoten bedrijfsonderdeel eerst moet zijn overdragen voordat de concentratie doorgang mag vinden. Dit heeft vanzelfsprekend grote gevolgen voor een transactie, aangezien marktpartijen er doorgaans belang bij hebben om een transactie zo snel mogelijk te voltooien en daarover ook de grootst mogelijke zekerheid willen hebben. Goed nieuws voor de transactiepraktijk is daarom dat het wetsvoorstel beoogt om dit standstill-vereiste uit lid 6 te schrappen, wat het nationale concentratietoezicht ook meer in lijn brengt met de regels die gelden op Europees niveau. Overigens bepaalt het huidige artikel 37 lid $6 \mathrm{Mw}$ al dat ingeval marktpartijen niet of niet

17 Geconsolideerde mededeling van de Commissie over bevoegdheidskwesties op grond van Verordening (EG) nr. 139/2004 betreffende de controle op concentraties van ondernemingen (PbEU 2008, C 95), punten 36-50.

18 M.T.P.J. van Oers \& R. Wesseling, T\&C Mededingingswet, Deventer: Wolters Kluwer 2020, aant. 3 onder d bij art. 30 lid 2 Mw. tijdig aan de gestelde voorwaarden voldoen, alsnog een vergunning is vereist. Dit vereiste zal in het nieuwe wetsvoorstel naar lid 4 worden verplaatst.

In een eerdere versie van het wetsvoorstel had het kabinet het vereiste opgenomen dat marktpartijen binnen één jaar na de mededeling dat geen vergunning is vereist of na het verstrekken van een vergunning, de concentratie moesten voltrekken. Deze toevoeging stuitte echter op veel kritiek in de openbare consultatie. Onder meer de Nederlandse Orde van Advocaten merkte terecht op dat er geen noodzaak is voor een beperking van de termijn waarbinnen een concentratie zou moeten worden voltrokken. Het kabinet heeft dit vereiste dan ook niet meer terug laten komen in de meest recente versie van het wetsvoorstel.

\section{Standstill-verplichting bij een openbaar bod (art. $39 \mathrm{Mw}$ )}

Artikel 39 lid $1 \mathrm{Mw}$ bepaalt dat de standstill-verplichting uit artikel 34 lid $1 \mathrm{Mw}$ niet geldt voor concentraties die tot stand komen via een openbaar overnamebod, als deze direct daarna alsnog aan de ACM worden gemeld. De voorgestelde wetswijzing beoogt ook artikel 39 lid 1 Mw zo dicht mogelijk aan te laten sluiten bij artikel 7 lid 2 EG-concentratieverordening. Hoewel er daarom enkele tekstuele wijzigen worden aangebracht, verandert artikel 39 lid 1 Mw inhoudelijk niet.

De uitzondering op de standstill-verplichting in het geval van een openbaar bod geldt vanzelfsprekend niet alleen voor de meldingsfase, maar ook voor de vergunningsfase. Om verwarring te voorkomen - nu lid 1 verwijst naar de standstill-verplichting uit de meldingsfase (art. $34 \mathrm{Mw}$ ) - wordt in het nieuwe artikel 39 lid $2 \mathrm{Mw}$ verduidelijkt dat de uitzondering van artikel 39 zowel in de meldingsfase als in de vergunningsfase geldt.

\section{Overige wijzingen}

Naast bovengenoemde wijzingen bevat het wetsvoorstel nog een tweetal technische wijzingen die zien op de definitie van een concentratie (art. 27 en $28 \mathrm{Mw}$ ). De wijzigingen zijn slechts tekstueel van aard en beogen de nationale formulering beter aan te sluiten bij de EG-concentratieverordening.

\section{Wijzigingen in het kader van de privaatrechtelijke handhaving van de mededingingsregels}

Ten slotte voorziet het wetsvoorstel in enkele tekstuele wijzigingen van artikel 6:193k Burgerlijk Wetboek (BW) in het kader van de privaatrechtelijke handhaving van de mededingingsregels.

Begin 2017 is de Implementatiewet richtlijn privaatrechtelijke handhaving mededingingsrecht in werking 
getreden. Hiermee is Richtlijn 2014/104/EU ${ }^{19}$ geïmplementeerd in Boek 6 van het BW en in het Wetboek van Burgerlijke Rechtsvordering. Richtlijn 2014/104/EG is alleen van toepassing op grensoverschrijdende inbreuken in de zin van artikel 101 en 102 VWEU en dit dan ook waar de implementatiewet en het huidige artikel 6:193k BW in voorzien. Zuiver nationale inbreuken op het mededingingsrecht vallen dus niet onder Richtlijn 2014/104/EG en artikel 6:193k BW voorziet hier ook niet in. De reden hiervoor is dat overeenkomstig Aanwijzing 331 van de Aanwijzingen voor de regelgeving de implementatiewet geen bepalingen bevat die verder gaan dan voor de implementatie noodzakelijk is en dus niet voorzien in zogenoemde 'nationale koppen'. In de memorie van toelichting bij de implementatiewet ${ }^{20}$ is destijds wel het voornemen geuit om in een separaat wetsvoorstel de bepalingen ook op zuiver nationale overtredingen van het mededingingsrecht van toepassing te verklaren, wat met het huidige wetsvoorstel is ingewilligd.

Blijkens de memorie van toelichting zal - niet verrassend - voor de privaatrechtelijke handhaving voor zuiver nationale inbreuken worden aangesloten bij het Europese mededingingsrecht: dezelfde aansprakelijkheids-, schadevergoedings- en bewijsrechtelijke regels zullen dan ook op zuiver nationale gevallen worden toegepast. ${ }^{21}$ Een andere toepassing zou het ongewenste effect kunnen hebben dat in soortgelijke gevallen de mate waarin de schade wordt vergoed uiteenloopt. Relevant is nog wel dat de uitleg van de artikelen uit de implementatiewet (en dus Richtlijn 2014/104/EG) is voorbehouden aan het Hof van Justitie. Met de inwerkingtreding van het wetsvoorstel is deze uitleg ook leidend als deze artikelen van toepassing zijn op zuiver nationale gevallen. Voor zover bepaalde begrippen uit de implementatiewet ook voorkomen op andere plaatsen in het Nederlands recht, kan dat leiden tot verschillende definities. Dat is op zichzelf niet nieuw - denk bijvoorbeeld aan het ondernemingsbegrip, dat een veel bredere betekenis heeft in het mededingingsrecht. De interpretatie van deze begrippen buiten de context van Boek 6, titel 3, afdeling 3B, BW inzake de schending van mededingingsrecht - bijvoorbeeld in de context van Boek 2 BW - blijft echter voorbehouden aan de nationale rechter.

\section{Conclusie}

De verwachting is dat het besproken wetsvoorstel zowel in de Tweede als Eerste Kamer niet tot veel controverse zal leiden, hoewel de tijd de precieze uitkomst uiteraard zal moeten uitwijzen. Zoals ook is af te leiden uit de titel van het wetsvoorstel zijn de voorgestelde wetswijzingen vooral 'technisch van aard'. Desalniettemin laat het kabinet met het wetsvoorstel zien dat het mededingingsrecht een belangrijke rol heeft in de samenleving, de agrarische sector daarvan niet uitgezonderd. Ondanks de dwingendrechtelijke aard van het mededingingsrecht zou het niet als belemmerend moeten worden ervaren, maar door ondernemingen moeten worden gezien als een middel tot een gelijk speelveld, hetgeen ook mogelijkheden en kansen biedt. Het zal daarom interessant zijn om de ontwikkelingen te blijven volgen en wij kijken met name uit naar de publicatie van de handreiking voor de landbouwsector volgend jaar. 